\title{
Earliest Dates of Microlithic Industries (42-25 ka) from West Bengal, Eastern India: New Light on Modern Human Occupation in the Indian Subcontinent
}

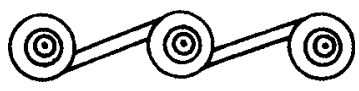

\author{
Bishnupriya Basak and Pradeep Srivastava
}

\begin{abstract}
Ancient microliths in South Asia have now been dated at least as early as 42-25 thousand years ago (ka), specifically at Mahadebbera and Kana, situated in the West Bengal area of India. This information adds substantively to scientific understanding of early human migrations and significant technological developments during the Pleistocene. Dating was possible through Optically Stimulated Luminescence (OSL) and the associated microliths and other artifacts were examined in detail. In relation to prior findings in the larger surrounding region, the new discoveries allow discussion of raw materials acquisition, possible travel routes, and other issues during a critical time of human evolutionary history. KeYwords: microliths, Late Pleistocene, South Asia, hominid migration, Optically Stimulated Luminescence (OSL).
\end{abstract}

NEW EVIDENCE HAS EXPANDED KNOWLEDGE OF AN ANCIENT MICROLITHIC TECHNOLOGY in South Asia within the range of 42-25 thousand years ago (ka). This work has contributed significantly to clarifying the origins of the microlithic technology and possible relations with larger issues of the development of modern human behaviors and the migration routes of Homo sapiens during the Late Pleistocene. Specifically, new investigations have supported dating through Optically Stimulated Luminescence (OSL), in concert with detailed documentation of microlithic assemblages at the sites of Mahadebbera and Kana, located in the West Bengal area of India (Figs. 1, 2).

Microlithic technologies have been linked confidently with complex human behavior in South Asia during the Pleistocene, specifically referring to microblades or non-geometric and geometric tools made on blade blanks during contexts prior to $12 \mathrm{ka}$ (Bar-Yosef and Kuhn 1999; Clarkson et al. 2009; James and Petraglia 2005; Mellars 2006). Evidence supporting the antiquity of microlithic industries and the "complete cultural package" (James and Petraglia 2005:S3) associated with it has been emerging from South Asia over the last few years (Clarkson et al. 2009; Lewis et al.

Bishnupriya Basak is an Assistant Professor (Senior grade) at the Archaeology Department of the University of Calcutta. Pradeep Srivastava is a Scientist ' $E$ ' at the Wadia Institute of Himalayan Geology in Dehradun. 


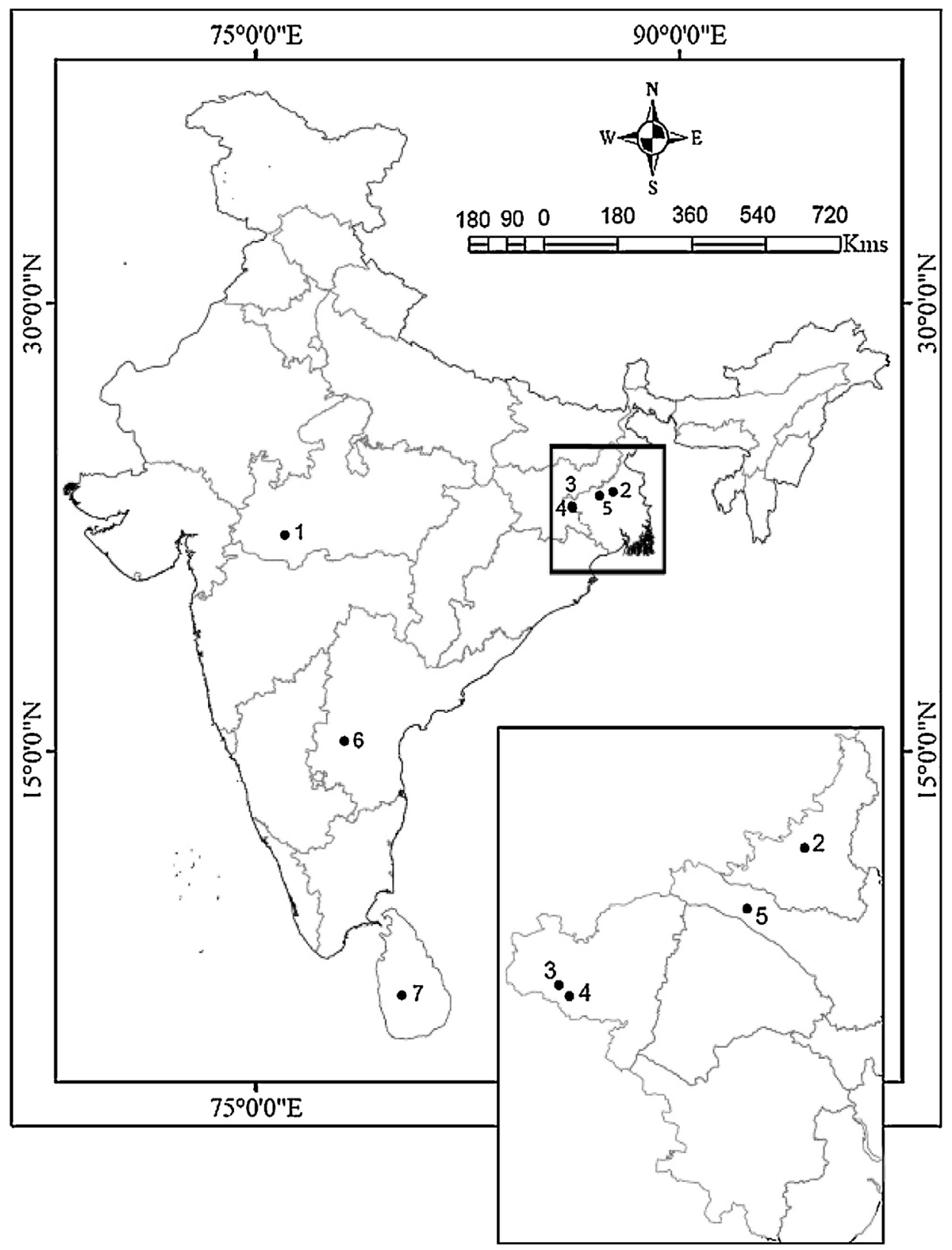

Fig. 1. General research region with locations of seven microlithic sites dated to Late Pleistocene: (1) Metakheri; (2) Sonajhuri; (3) Mahadebbera; (4) Kana; (5) Birbhanpur; (6) Jwalapuram; (7) BatadombaLena. 


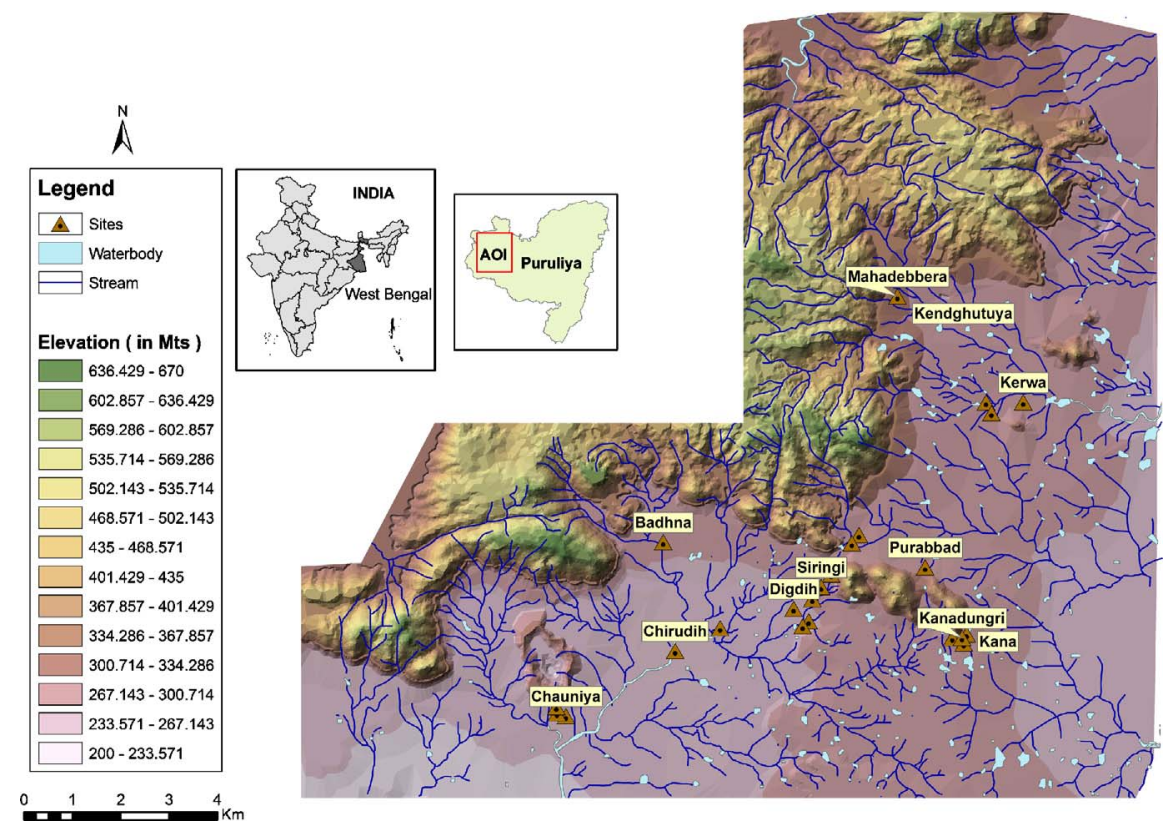

Fig. 2. Locations of 10 microlithic sites dated to Late Pleistocene, shown on digital elevation model of the study area of interest (AOI) (base image Survey of India topographical sheet 731/4).

2014; Mishra et al. 2013; Roberts et al. 2015). The dating has now been pushed back to $45 \mathrm{ka}$ at sites such as Metakheri in Madhya Pradesh in Central India (Mishra et al. 2013; cf. Groucutt et al. 2015). Considerable diversity has been noticed in the technology through time, as at Jwalapuram (Clarkson et al. 2009), and also between sites, as when comparing findings at Metakheri (Mishra et al. 2013) with Jwalapuram (Clarkson et al. 2009).

The dating of microliths in South Asia has been much debated. There has also been controversy concerning how the dated assemblages may have reflected ancient human behaviors and migration patterns during the Pleistocene (Dennell and Petraglia 2012; Groucutt et al. 2015; Mellars et al. 2013; Petraglia et al. 2010). Central to the debate has been the appearance of an older Middle Palaeolithic technology apparently followed by the later microlithic technology of our present focus, which has been documented from different archaeological sites and regions (Blinkhorn et al. 2015; Boivin et al. 2013; Clarkson et al. 2009). Two perspectives prevail on when Homo sapiens entered South Asia: it may have occurred around $55-50 \mathrm{ka}$ in association with coastal migration, or it may go back even earlier, to around $75 \mathrm{ka}$, in association with a Middle Palaeolithic point technology that continued into a later microlithic technology.

Taking the first viewpoint, Mellars and colleagues (2013) cite the distribution of microlithic and geometric tool kits around the Indian Ocean rim as evidence for a dispersal into South Asia by a coastal route around 55-50 ka. Mellars and colleagues (2013) and Mishra, Chauhan, and Singhvi (2013) have noted similarities between this microlithic technology and the Howiesons Poort (HP) findings in South Africa, all 
estimated within a similar chronological period. However, recent studies have highlighted the diversity of the HP technology.

Archaeologists favoring the second viewpoint argue that the microlithic assemblages reflect technological continuity from the Middle Palaeolithic onwards, occurring through the Toba eruption of $75 \mathrm{ka}$ (Blinkhorn et al. 2013; Boivin et al. 2013; Petraglia et al. 2010). For instance, Blinkhorn, Achyuthan, and Ajithprasad (2015) documented a point technology in the Middle Palaeolithic assemblages, seen at a few sites in the Thar Desert of western India, that are similar to contemporaneous technologies in North Africa and Arabia. Together, these findings potentially reflect an eastward dispersal of Homo sapiens during the Late Pleistocene. Distinctive Levallois-type stone blade production was evident in the cores and the flakes in the Thar Desert assemblages. Production involved removing one long flake from a core, followed by flake-reduction around one side of the large removed flake; this is internationally known as Levallois technology. In addition to observations in the Thar Desert sites, similar Levallois-type retouched points were found much farther southward in Jurreru Valley in contexts of c. $75 \mathrm{ka}$.

An apparent change toward specialized technology in microlithic tools has been noted c. 35-28 ka, coincident with a demographic expansion as inferred through genetics studies (Petraglia et al. 2009). This timing would have been during the Last Glacial Maximum (LGM), wherein extreme aridity and other environmental factors likely occasioned technological innovations, including a change in microlithic tools among other possibilities. Within peninsular India during the time range of $35-25 \mathrm{ka}$, a semi-glacial mosaic environment was comprised of deserts, savannah, tropical deciduous woodlands, and limited tropical forests. Against this diverse ecological backdrop, human populations would have decreased in the marginal areas while increasing elsewhere. For instance, deciduous zones exhibited a five-fold increase in the numbers of recorded sites.

The change in microlithic tools during the LGM overall may suggest a technological specialization through this period, wherein microliths were used as components of arrows or spears during times of stressed hunting trips. Backed blades first appeared about $34 \mathrm{ka}$ and subsequently became more numerous through time (Clarkson et al. 2009). Other indicators were noted in raw material use, reduction intensity, and artifact recycling.

Recent studies at two sites have contributed new information about the environmental setting, dating, and technological aspects of microliths in South Asia. The information reported here is from the Mahadebbera and Kana sites in the West Bengal area, dated by OSL at 42-25 ka (Basak et al. 2014) (Figs. 1, 2). These results have provided so far the only dated assemblages belonging to this period in the surrounding region, but they can be interpreted in relation to other known sites to reveal more in total about past landscape use (Basak 2001, 2005, 2008). This investigation is one of very few studies in Bengal to accommodate a multi-disciplinary approach, ideally encouraging further research (Basak 1997).

MAHADEBBERA AND KANA: LOCATION IN A PEDIMENT LANDSCAPE

Within the West Bengal region, the sites of Mahadebbera and Kana occupy a pediment (i.e., a broad sloping rocky surface extending from the foot of a hillslope) in the 
Ayodhya Hill Range, described as denudational Precambrian hills with tors, at 300-700 $\mathrm{m}$ above sea level (asl) (Fig. 2). The rock types are phyllite, mica schist, quartzite, amphibolites, epidorites, granite-gneiss, quartz-pegmatite vein, and quartz breccias. The pediment surface was emplaced in the Manbazar Formation of the Kumari Basin (Chattopadhyay 1992), characterized by terraces and badlands that also extend over the surrounding areas of Ayodhya Hills.

The entire region is drained by the minor tributaries or low-order streams of the Kumari Sankh river systems. A number of these drainage channels extend from the hillslopes toward the lower surface. These drainages effectively transport the monsoon runoff and sediment load of the region.

The colluvial context of the microlithic industries forms part of the pediment surface. The hillslope colluvium is primarily a gravelly silty sand derived from Precambrian rocks of the denudational hills through soil creep processes. The surface has been covered by scattered vegetation of tropical dry deciduous type and has been subject to severe deforestation.

Pleistocene or early Holocene age sites are known to exist in a number of colluvial landscapes in foothill regions (Bettis 2003:788). While the source material of sediments usually derived from positions immediately upslope, archaeological deposits tended to occur on the stable surfaces that periodically developed throughout the process of colluvial formation. Different lensing or layering could potentially be detected within a stratigraphic profile of a colluvial depositional unit, wherein artifacts such as microliths might be observed in specific concentrations.

Several microlith-bearing sites were identified in four major zones of the hillslope colluvial context. Many of these sites were located on the banks of low-order channels draining the slopes of the hills (Basak 2001, 2005, 2008). A typical tor landscape is seen at Kana and Siringi, where boulders are perched atop one another and artifacts are embedded in a thin colluvial deposit.

The sites of Mahadebbera and Kana were identified as bearing high research potential due to their artifact densities and excellent exposure of badland formation showing the colluvial context. Mahadebbera $\left(23^{\circ} 11^{\prime} 38.77^{\prime \prime} \mathrm{N}, 86^{\circ} 11^{\prime} 53.3^{\prime \prime} \mathrm{E}: 304 \mathrm{~m}\right.$ asl $)$ is an area $72 \mathrm{~m} \times 50 \mathrm{~m}$ in the middle of forested land; it is located within $500 \mathrm{~m}$ northwest of Ghatbera village on the left bank of a low-order stream in the catchment area of the Kumari river. Kana $\left(23^{\circ} 07^{\prime} 42.7^{\prime \prime} \mathrm{N}, 86^{\circ} 12^{\prime} 47.5^{\prime \prime} \mathrm{E}: 288 \mathrm{~m}\right.$ asl $)$ is located about $500 \mathrm{~m}$ northwest of Kana village at the foothill of an inselberg (i.e., an isolated hill).

During 2011-2012 and 2012-2013, detailed studies were made of the stratigraphy and the microlithic industry at Mahadebbera and Kana (Basak 2013). The spatial limits of the sites were defined by the surface-detectable artifact distribution; maps were prepared using surveyor's tape and compass. The results of surface collections, sample excavations, OSL dating, and analysis of artifacts are presented here.

\section{STRATIGRAPHY AND CHRONOLOGY}

In the first excavation at Mahadebbera (MDB1), three major stratigraphic units were observed in a total depth of $3.29 \mathrm{~m}$ (Fig. 3). Artifacts were found intermittently through Unit 1 (0.15-1.55 m depth), consistently throughout Unit 2 (1.55-1.81 m), and not at all in Unit $3(1.81-3.29 \mathrm{~m})$. The microliths in Unit 2 were associated with OSL dating of $31 \pm 3 \mathrm{ka}$ (described below). Unit 1 was made of indurated, moderately 


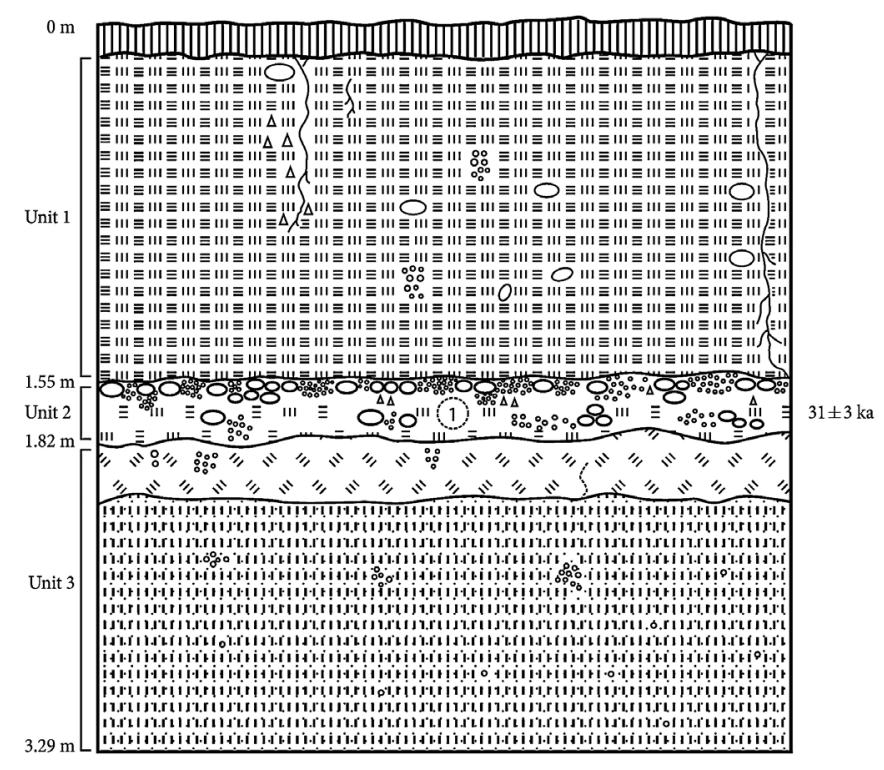

\begin{tabular}{|c|c|}
\hline & Surface humus \\
\hline 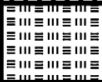 & Silty sand \\
\hline 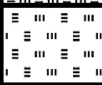 & $\begin{array}{l}\text { Colluvium in silty sand } \\
\text { matrix bearing artifacts }\end{array}$ \\
\hline 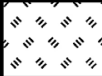 & Silty sand \\
\hline 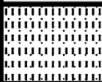 & Silty sand \\
\hline & OSL sample \\
\hline 80 & Cobbles \\
\hline$\frac{\Delta}{\Delta \Delta}$ & Microliths \\
\hline 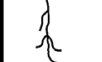 & Tree root \\
\hline $\begin{array}{r}\because \because 0 \\
\because \because 0 \\
\because\end{array}$ & Pellets \\
\hline & Tree root \\
\hline
\end{tabular}

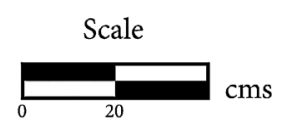

Fig. 3. Section drawing of first excavated trench at Mahadebbera (MDB1), southern section stratigraphy.

pedogenized, reddish silty sand. Toward the base of this unit, sporadic occurrences of poorly sorted clasts of schist, quartz, quartzite, and feldspar were visible. Unit 2 was composed of a reddish silty sand, with cobbles of weathered schist, vein quartz, and quartzite (almost 90 percent of the total deposit in this unit). Moderate pedogenesis was indicated in Unit 1 and Unit 2 by crumbs and flaky peds. Unit 3 was constituted of red loose silty sand.

In the second excavation at Mahadebbera (MDB2), the same stratigraphic sequence was observed in a total depth of $2.2 \mathrm{~m}$, with artifacts distributed intermittently in Unit 1 and consistently in Unit 2 (Fig. 4). From this second profiled area, two OSL dating samples from Unit 1 produced results of $29 \pm 2 \mathrm{ka}$ and $25 \pm 3 \mathrm{ka}$; a single OSL date from Unit 2 was $34 \pm 3 \mathrm{ka}$ (described below). Unit 1 was measured at $0.15-1.9 \mathrm{~m}$. Unit 2 occurred at 1.9-2.2 m. The top of Unit 3 was encountered at $2.2 \mathrm{~m}$, but it was not excavated in this case. Unit 3 was not exposed in this section.

The entire deposit at Mahadebbera was part of a colluvial fill that developed as an apron over the Precambrian bedrock. This apron ranged in elevation from $304 \mathrm{~m}$ (surface of the excavated area) to $290 \mathrm{~m}$ (channel level of the low-order stream of the Kumari described above). The mode of deposition can be attributed most likely to soil creep, through sheet flow with occasional but strong episodes of flows of rainwater during summer southwest monsoon events throughout the Pleistocene. 

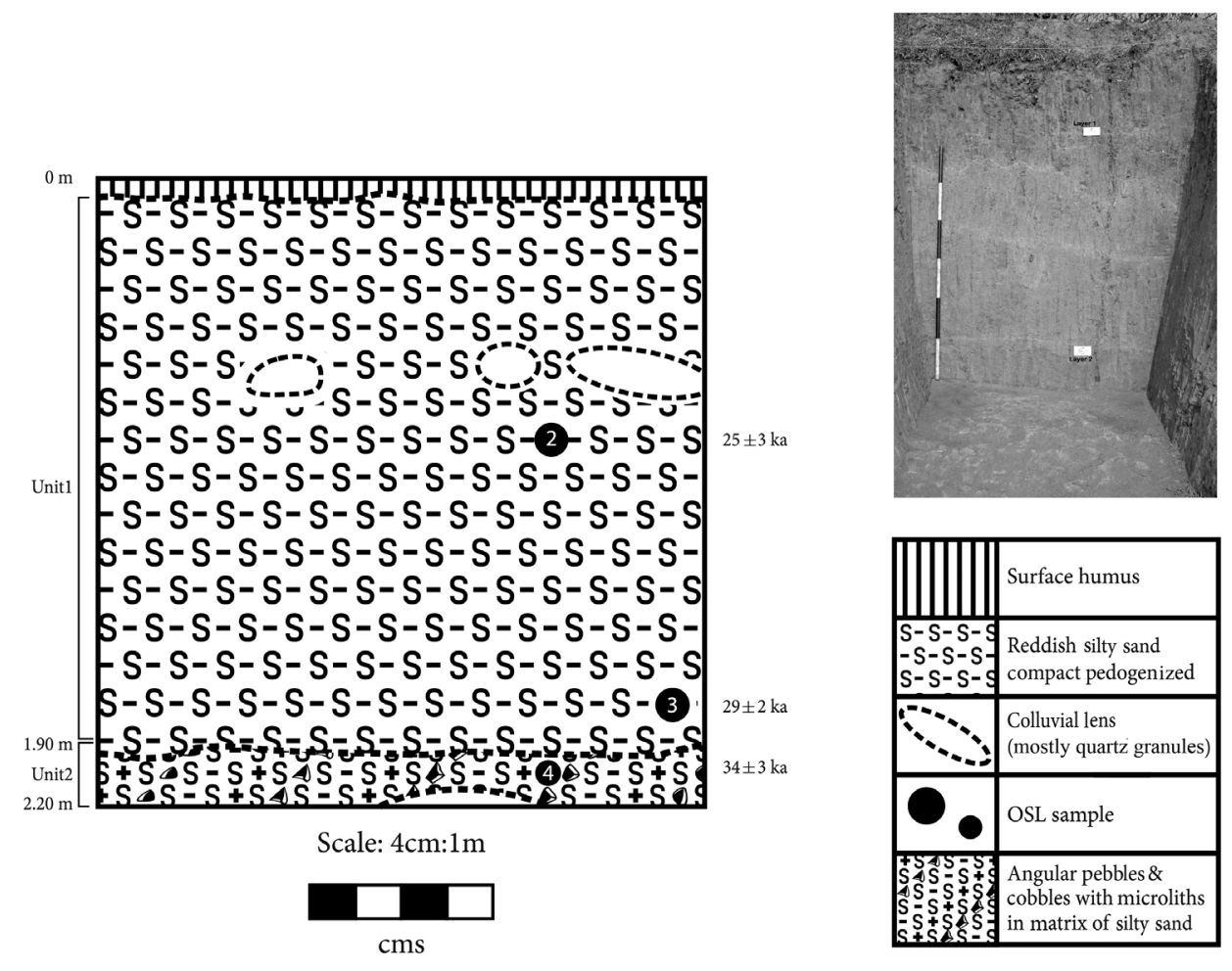

Fig. 4. Section drawing of second excavation at Mahadebbera (MDB2).

The deposition of colluvium resembled a series of episodes rather than continual build-up. Such a context was reflected in weak or moderate pedogenesis, wherein the microliths were emplaced in a number of different stabilized gravel layers. The Kumari River has cut through this colluvium deposit, as seen in many exposed sections within a $10 \mathrm{~km}$ radius of the site.

At Kana, an extensive badland was embodied in the colluvium with an apron of brown sediment approximately 5-6 $\mathrm{m}$ thick. A section was cleared to $2.47 \mathrm{~m}$ depth, exposing three major stratigraphic units (Fig. 5). Unit $1(0-1.15 \mathrm{~m})$ was a reddish silty sand with sparse quartz granules. Unit $2(1.15-2.47 \mathrm{~m})$ consisted of a gravelly silty sand resting over a third stratigraphic unit that was observed but not excavated. Unit 3 was described as a mottled greenish gray clayey silt, comprising the base level of the exposed badland.

In the investigation at Kana, artifacts were consistently found within a depth range of 1.34-1.63 m, inside Unit 2 of the stratigraphic sequence. OSL dating of Unit 2 here provided a result of $42 \pm 4 \mathrm{ka}$ (described below). Owing to erosional processes at the site, artifacts were distributed widely in the gullies of the badland terrain, extending over an area of $150 \mathrm{~m} \times 150 \mathrm{~m}$. As at Mahadebbera, the spatial limit of the primary artifact concentration was mapped by surface-detectable artifacts.

For OSL dating, five samples were collected from the sedimentary contexts most directly related to the concentrations of microliths, wherein the microliths had been deposited within the same depositional contexts of the sediments being dated directly by OSL. OSL Sample 1 was collected from a depth of $1.80 \mathrm{~m}$ within Unit 2 of the first 


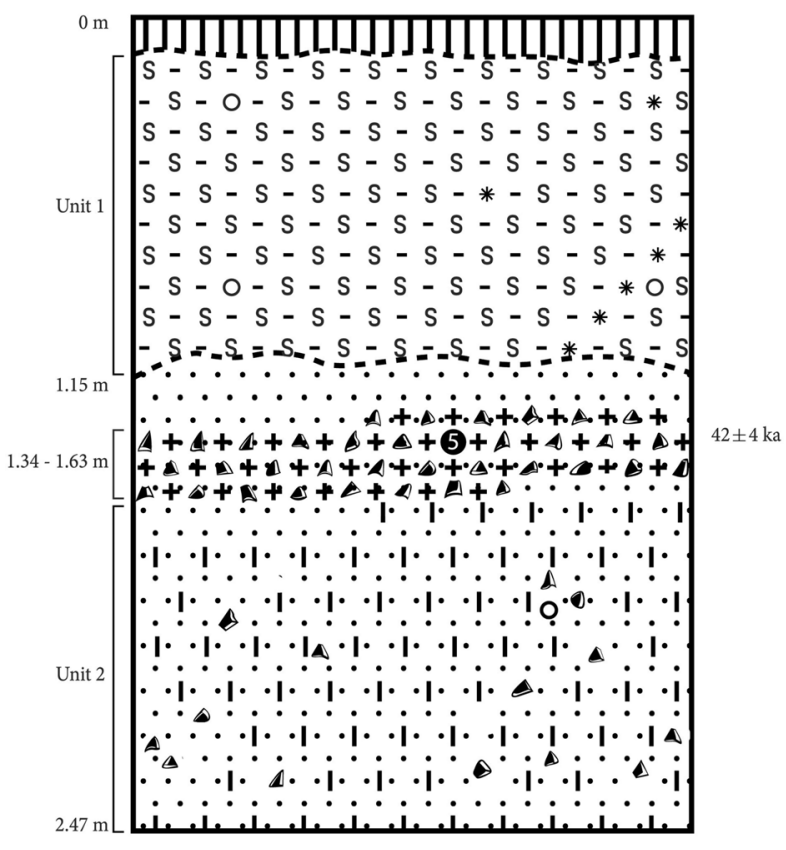

Scale: $4 \mathrm{~cm}: 1 \mathrm{~m}$
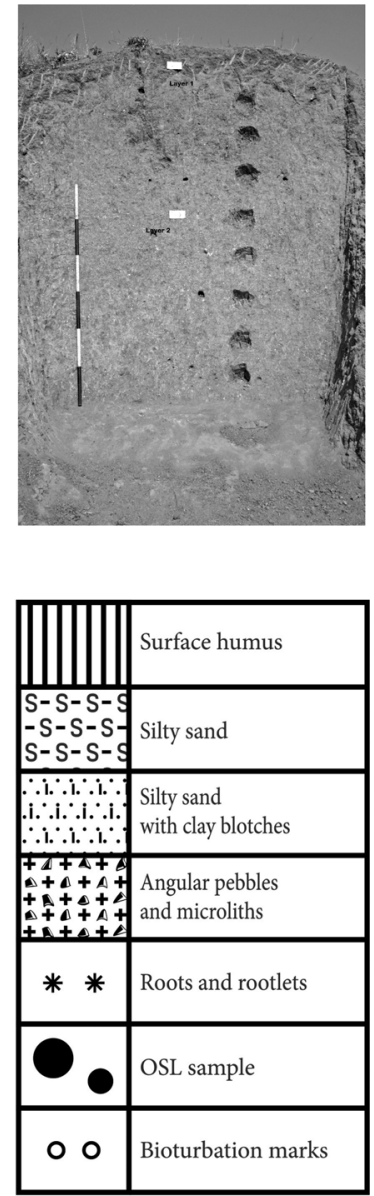

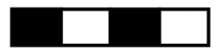

$\mathrm{cms}$

Fig. 5. Section drawing of cleared section at Kana.

excavated section at Mahadebbera. From the second section at Mahadebbera, Sample 2 $(0.69 \mathrm{~m})$ and Sample $3(1.8 \mathrm{~m})$ were collected from Unit 1. Sample 4 was collected from a depth of $2.03 \mathrm{~m}$ within Unit 2. At Kana, Sample 5 was collected from a depth of $1.45 \mathrm{~m}$ within Unit 2.

OSL dating relies upon the ability to measure the amount of luminescence stored in quartz grains, giving an approximation of the last time when those grains were exposed to sunlight (Aitken 1998). For this reason, the sampling procedure involved protocols for obtaining quartz grains from deep within the sedimentary profile away from modern sunlight. The profile sections were draped in a thick black cloth and the samples were collected in custom-designed steel pipes. The pipes were immediately sealed and then sent to the Wadia Institute of Himalayan Geology for analysis.

All OSL measurements were performed with a Riso luminescence reader, using a minimum age model developed by Ray and Srivastava (2010). The minimum age 
model accounts for the likelihood of bleaching of the sediments in hillslope debris. Chemical pretreatment and sample processing followed previously established practices (Ray and Srivastava 2010). Single Aliquot Regeneration (SAR) protocol was used to estimate palaeodose (Murray and Wintle 2000), while dose rates were computed using values of $\mathrm{U}$, Th, and $\mathrm{K}$ derived from $\mathrm{X}$-ray fluorescence (XRF). The cosmic gamma contribution was assumed to be $150 \pm 30$.

The OSL results ranged from $42 \pm 4 \mathrm{ka}$ through $25 \pm 3 \mathrm{ka}$. Sample 1 from the first profile at Mahadebbera gave a date of $31 \pm 3 \mathrm{ka}$. Samples 2, 3, and 4 from the second profile at Mahadebbera provided dates of $25 \pm 3 \mathrm{ka}, 29 \pm 2 \mathrm{ka}$, and $34 \pm 3 \mathrm{ka}$, respectively. Sample 5 from Kana yielded the oldest measured date of $42 \pm 4 \mathrm{ka}$.

According to these results, human activity occurred on the colluvial pediment surface during the Pleistocene. Examples of the products of these ancient activities were preserved in the archaeological records at Mahadebbera (Fig. 6) and Kana (Fig. 7). Similar circumstances of site stratigraphy were observed at several other sites in the surrounding region (see Fig. 2), suggesting roughly equivalent ages and contexts for comparison with the detailed findings at Mahadebbera and Kana.

\section{THE LITHIC ASSEMBLAGES AT MAHADEBBERA AND KANA}

The recovered flakes, cores, debitage, and other pieces provided a substantial basis for ascertaining ancient microlithic technology and potentially how it functioned within the social and technological world of the people who produced it during the Pleistocene at Mahadebbera and Kana (Fig. 8). Toward this goal, individual artifacts were described in terms of how they were produced and how they related with one another, as these reflect the different technical choices in a chaîne opératoire of obtaining the raw materials, preparing the initial cores and primary flakes, and finishing the products of microliths. Individual artifacts can reveal specific aspects of the choices that people made during the chain of decisions and actions of the chaine opératoire.

The stone artifacts from Mahadebbera were collected both from controlled excavations and from naturally exposed profiles (Figs. 9, 10). The excavations at Mahadebbera recovered 100 artifacts from Units 1 and 2 (Table 1). A further 794 artifacts were collected and recorded in $5 \mathrm{~m} \times 5 \mathrm{~m}$ grid provenience from exposed profiles on the badlands cliffs.

A total of 84 artifacts were collected from Unit 1 at Mahadebbera. The collection included 48 flakes, 1 retouched flake, 9 cores, 2 broken microblades, 7 chunks, and 17 chips. Specifically, 3 of the cores and 27 of the flakes in this collection were retrieved from clusters at $0.69 \mathrm{~m}$ (associated with an OSL date of $25 \pm 3 \mathrm{ka}$ ) and $1.8 \mathrm{~m}$ (associated with an OSL date of $29 \pm 2 \mathrm{ka}$ ).

From Unit 2, the collected artifacts included 11 flakes and 5 chips. The flakes showed prominent blade scars, so these items were interpreted as microlithic debitage. In terms of raw material and overall flaking technology, the characteristics were consistent with their artifacts from Unit 1.

The overall occurrence of artifacts appeared less dense in the controlled excavation profiles when compared with the larger exposed surfaces of the badland cliffs, likely due to the differential effects of erosional processes. The particles of colluvium have eroded from the naturally exposed surfaces, but the heavier pieces of microlithic artifacts have remained there, resulting in a "lag surface" or "deflated deposit." The interior spaces of the colluvium units have not eroded as much as their exterior 


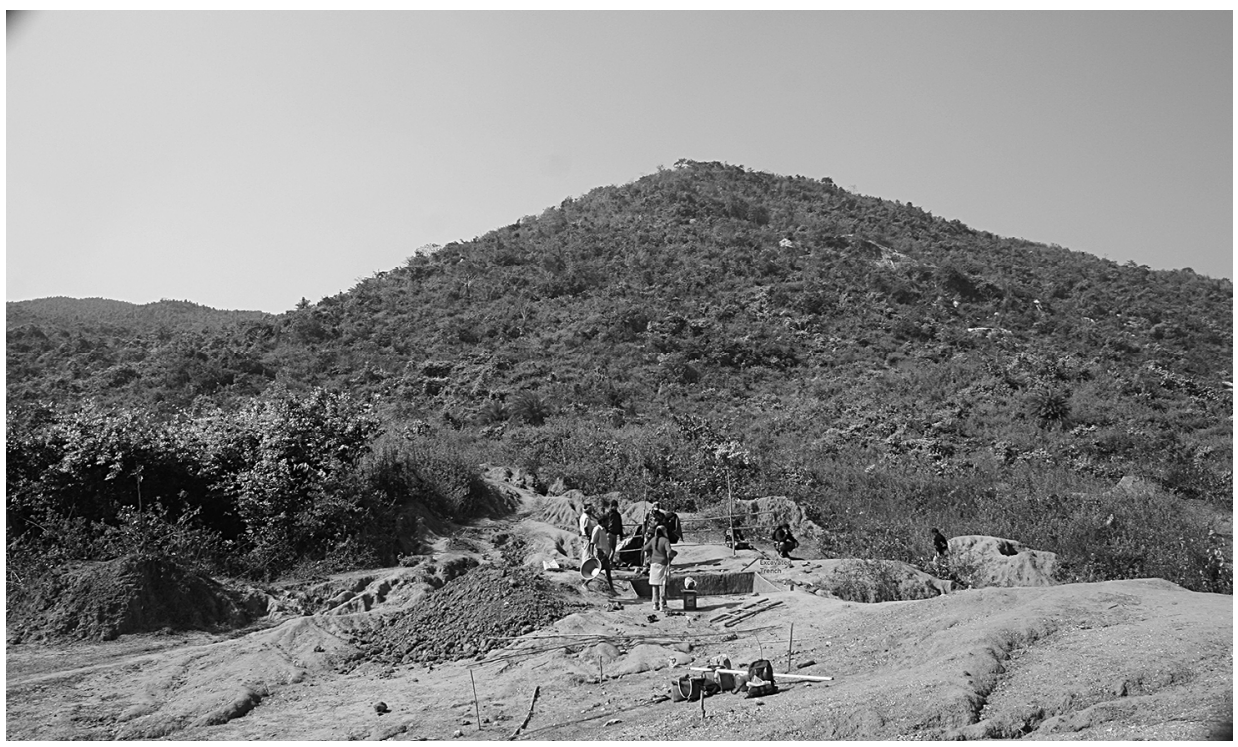

Fig. 6. Topographic setting at Mahadebbera.

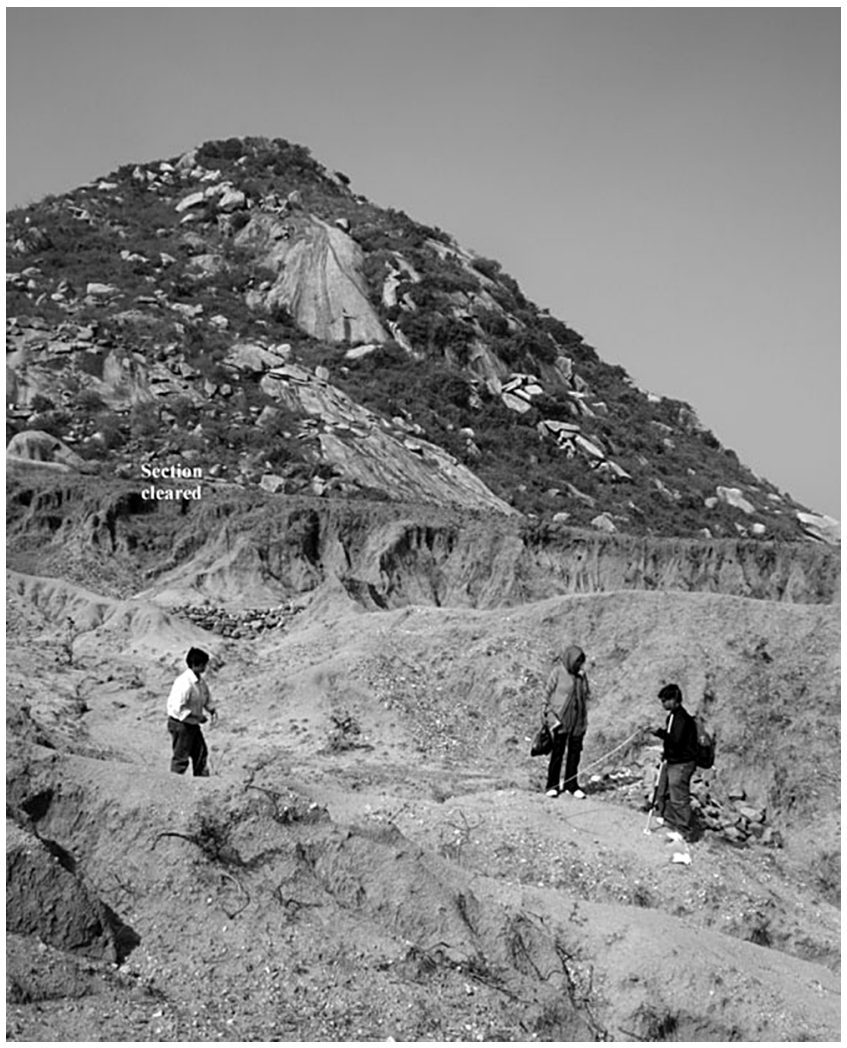

Fig. 7. Badland topography and the section cleared at Kana. 


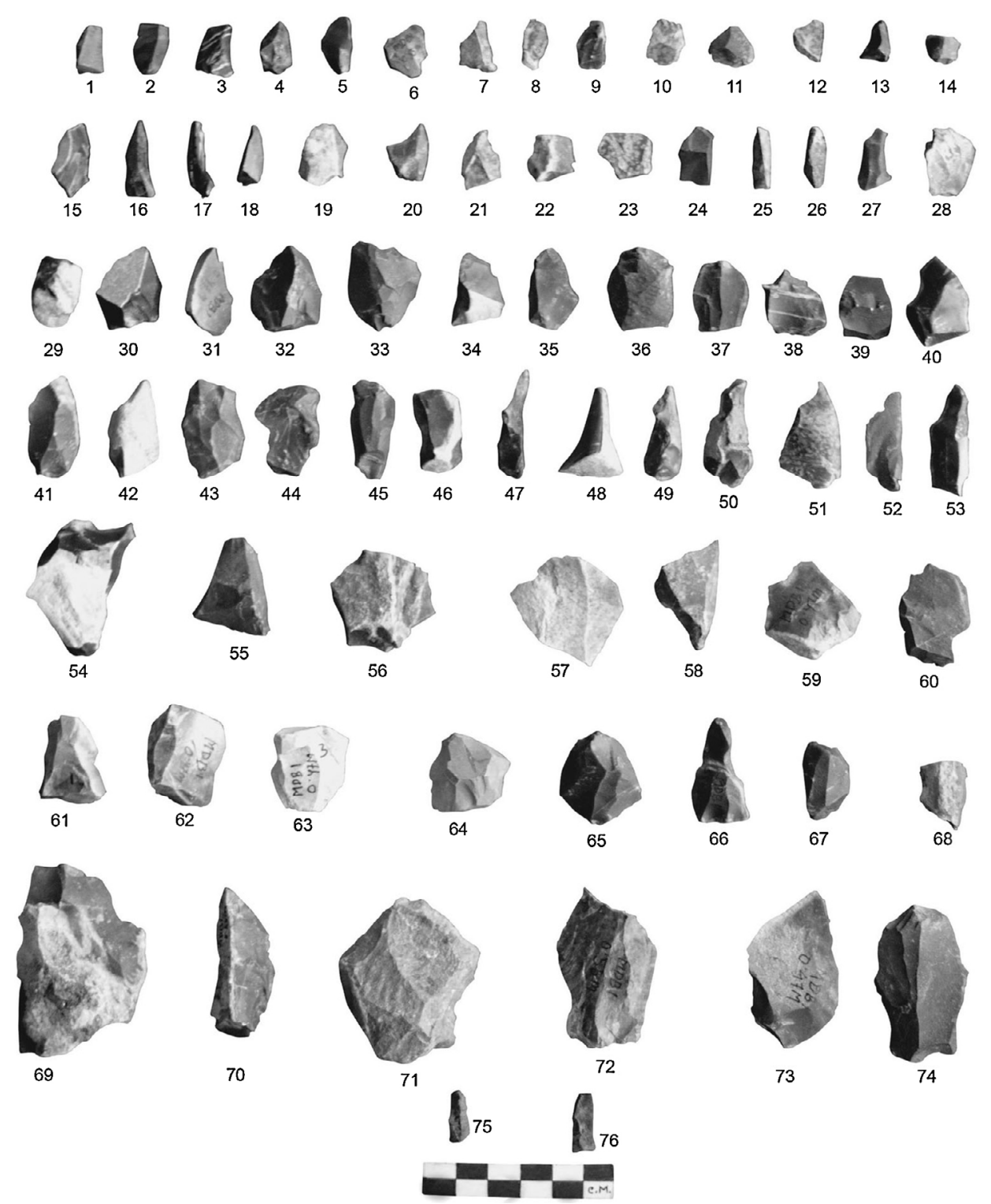

Fig. 8. Excavated assemblage at Mahadebbera: (1-14) chips; (15-60) flakes; (61-68) cores; (69-74) flakes; (75-76) blades.

exposed portions, resulting in a greater ratio of sediment to artifacts in the less eroded contexts. Materials from both contexts have been useful for increasing observable sample of artifacts and clarifying their chronological parameters.

Consistently in Units 1 and 2 at Mahadebbera, the microlithic artifacts had mostly been produced from raw material of felsic tuff, with quartzite and chert very sparingly represented. According to a petrographic analysis of four of the artifacts by the Geological Survey of India, eastern region, Kolkata, all four of these items were composed of felsic tuff with almost identical mineral composition. The major 


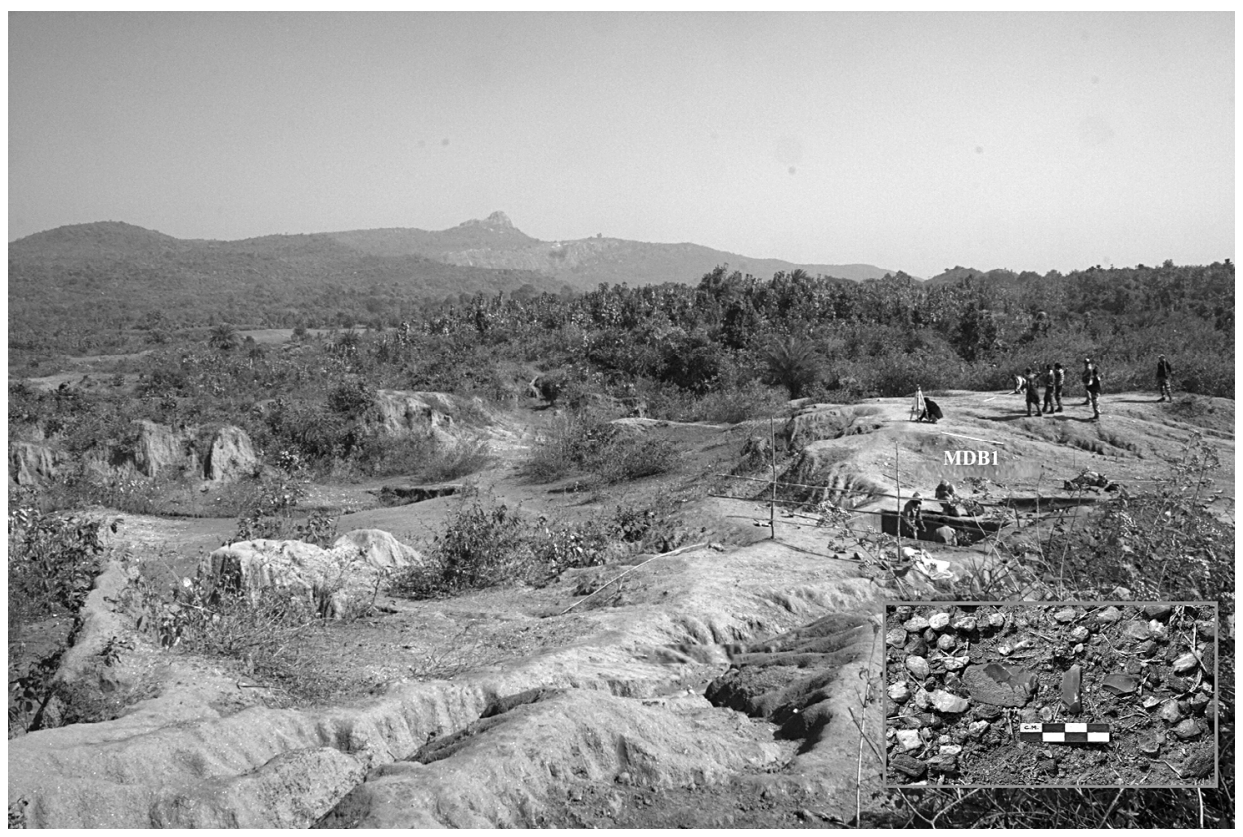

Fig. 9. Mahadebbera site showing location of excavated trench (MDB1); inset photograph shows artifacts exposed at the base of MDB1.

constituent minerals were quartz, feldspar, and biotite, with minor actinolite, tourmaline, and apatite.

Felsic tuff was never available at Mahadebbera or in its immediate vicinity, but it has been reported as occurring in bands $15-20 \mathrm{~km}$ south of the site (Acharyya et al. 2006). These circumstances suggest that the original raw material acquisition must have occurred outside the site of Mahadebbera, and then the materials were transported to the site. The initial stages of working the raw materials may have occurred closer to

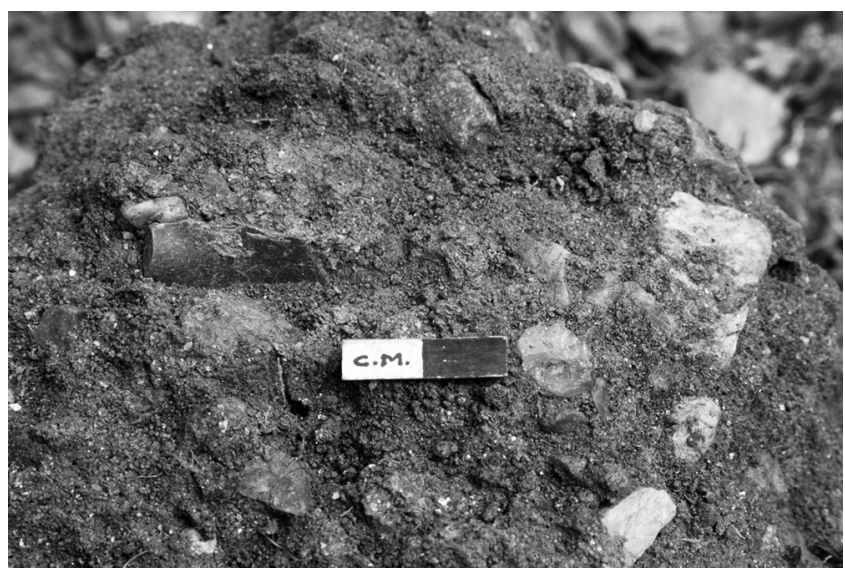

Fig. 10. In situ artifacts at Mahadebbera. 
Table i. Artifact Types from Mahadebbera, Excavated Trench and Second Section

\begin{tabular}{llclll}
\hline TYPE & NUMBER, $\%$ & $\begin{array}{c}\text { AVERAGE } \\
\text { WIDTH (CM) }\end{array}$ & $\begin{array}{c}\text { AVERAGE } \\
\text { LENGTH (CM) }\end{array}$ & $\begin{array}{c}\text { MAXIMUM } \\
\text { LENGTH (CM) }\end{array}$ & $\begin{array}{c}\text { MINIMUM } \\
\text { LENGTH (CM) }\end{array}$ \\
\hline Cores & $9,9 \%$ & & 2.83 & 4.34 & 2.09 \\
Flakes & $59,59 \%$ & 1.83 & 2.88 & 5.8 & 1.37 \\
Retouched flakes & $1,1 \%$ & $\mathrm{n} / \mathrm{a}$ & $\mathrm{n} / \mathrm{a}$ & $4.94^{\mathrm{a}}$ & $\mathrm{n} / \mathrm{a}$ \\
Broken microblades & $2,2 \%$ & 0.75 & 1.52 & 1.56 & 1.49 \\
Chunks & $7,7 \%$ & & 2.67 & 3.14 & 1.85 \\
Chips & $22,22 \%$ & $\mathrm{n} / \mathrm{a}$ & $\mathrm{n} / \mathrm{a}$ & $\mathrm{n} / \mathrm{a}$ & $\mathrm{n} / \mathrm{a}$ \\
\hline
\end{tabular}

${ }^{\mathrm{a}}$ Length of single retouched flake.

their natural source, followed by later stages in the chaine opératoire being represented at the site as it has been detected today.

The primary stage of reduction from raw material was not observed in the artifact collections from Mahadebbera; only the later stages of working with prepared cores and secondary flakes were confirmed (Figs. 11-15). No raw material nodules were observed at all. Cortex was minimal on the pieces that had already been removed from their parent materials; deliberate decortication to access the interior portions of the raw materials seems to have occurred. In these cases, the cores had already been prepared by removing the cortex; the inferred initial reduction tasks must have occurred elsewhere, most likely closer to the geological origin of the felsic tuff.

The excavated microlithic assemblage from Mahadebbera for the most part represented the middle and later stages of debitage of microblade production. No rough-out cores were found, but the prepared cores were measured between 2.11 and $3.29 \mathrm{~cm}$, with a mean length of $2.64 \mathrm{~cm}$. Two broken blades were $1.75 \mathrm{~cm}$ and $1.61 \mathrm{~cm}$ in length, corresponding with the sizes of the cores. The angle between the striking platform surface and the blade detachment surface of the prepared cores was around $70-80^{\circ}$ which suggested exhaustive exploitation prior to discard. Only a single flake showed re-touching.

The microblade artifacts at Mahadebbera conformed with established definitional criteria for microblades as being less than $4 \mathrm{~cm}$ long and showing little or no cortex on dorsal surfaces (Bar-Yosef and Kuhn 1999; Clarkson et al. 2009). This is true of both the excavated and explored assemblage. In the explored assemblage, nearly 99 percent were less than $3 \mathrm{~cm}$ long and 85 percent were less than $1 \mathrm{~cm}$ wide. A solitary item exceeded $3 \mathrm{~cm}$ at its maximum axis. Cortex was minimal or entirely absent in most cases, as already noted. Additional diagnostic attributes accorded with microblade definitions by Lewis, Perera, and Petraglia (2014), including at least one longitudinal ridge, parallel to subparallel lateral margins, and dense concentration of dorsal scars. Many of the microblades were broken, but the context of breakage has not yet been ascertained.

The microblades had been fashioned into "backed blades," with backed or re-touched working along one margin opposite the cutting edge. Variable shapes included points, lunates, triangles, and a single instance of a burin or scraper (Table 2; Figs. 11, 12). All of the backed blades measured less than $3 \mathrm{~cm}$ at their maximum-length axis, and 87 percent measured less than $1 \mathrm{~cm}$ in width as well.

Not all of the recovered flakes were microblades, so a size-category subgrouping was conducted to identify the range of represented artifacts (Table 3). While all of the items 


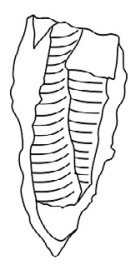

1

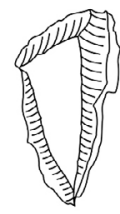

2

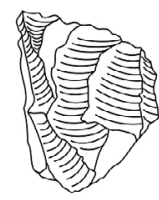

3

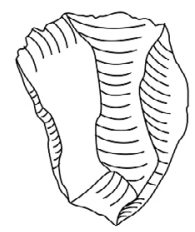

4

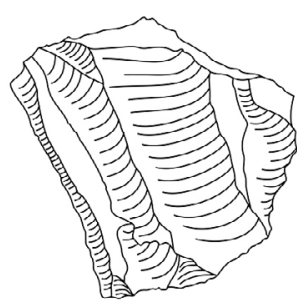

5

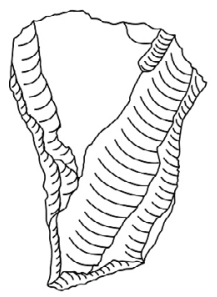

6

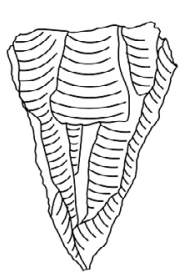

7

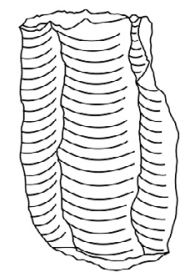

8

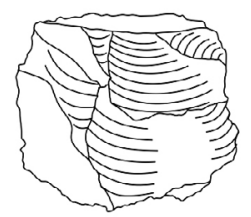

9

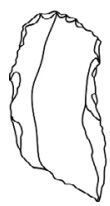

10

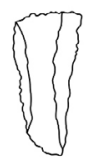

11

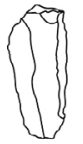

12

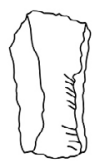

13

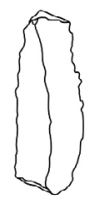

14

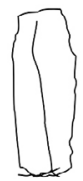

15

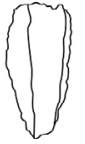

16

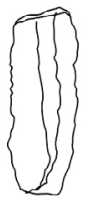

17

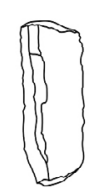

18

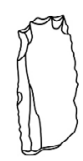

19

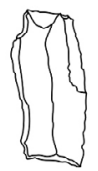

20

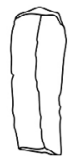

21

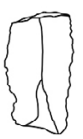

22

Fig. 11. Microblade cores and microblades from Mahadebbera: (1-9) microblade cores; (10-16) complete microblades; (17-22) microblades snapped at proximal/distal ends. Scale bars are in $1 \mathrm{~cm}$ increments.

could be considered part of a microlithic assemblage, they may have related to different stages of manufacture or to different end products. The maximum-axis lengths were subgrouped as small (up to $2 \mathrm{~cm}$ ), medium $(2-4 \mathrm{~cm})$, and large $(4-6 \mathrm{~cm})$. These findings were most relevant when compared with the prepared cores to ascertain how the individual flakes may have related within larger production sequences or chaîne opératoire.

Of the prepared cores found at Mahadebbera, nearly all showed clear flake scarring indicating substantial usage before being discarded. Close to 18 percent of the cores 


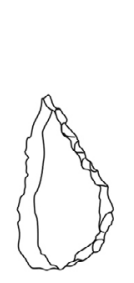

1

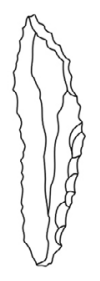

2

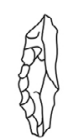

3

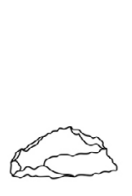

9

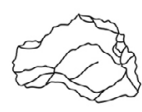

4

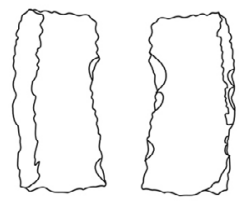

10

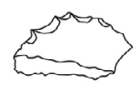

5

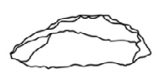

6

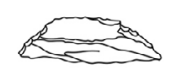

7

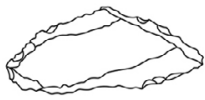

8

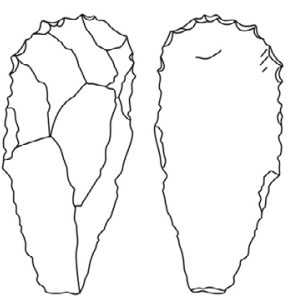

12

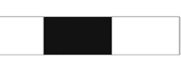

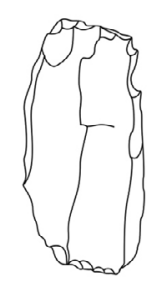

13

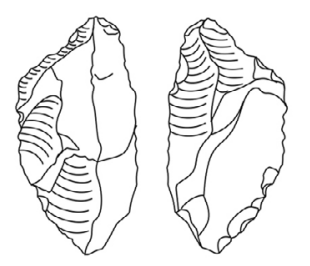

14

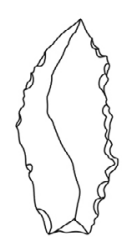

15

Fig. 12. Microliths, backed blades, and flakes with retouching on margins from Mahadebbera: (1-3) points; (4-7) lunates; (8-9) triangles; (10-11) backed blades; (12-15) flakes with retouching on margins. Scale bars are in $1 \mathrm{~cm}$ increments.

exhibited no usable angles for continued blade removal. The ratio of 515 flakes to 70 cores (7.36:1) revealed the extent of flaking activity at the site; on average, more than seven flakes had been removed from each core. Recycling or re-use was seen in 2 percent of the debitage flakes, in the forms of re-touching along any one margin of the flake on the dorsal or ventral surface (Fig. 12).

In principle, some of the cores could have been abandoned during any stage of manufacture, not necessarily worked to the point of absolute exhaustion (Finlay et al. 2000). In recognition of this possibility, the numbers of striking platforms per bladecore surface were recorded, as were the directions of blade removal, as approximations of the extent of flaking prior to discard of each core. Blade cores with a double platform were most common (50 percent), followed closely by cores with a single platform (44.8 percent); cases of multiple $(3+)$ platforms were rare $(5.2$ percent). Blades were removed from platforms in single directions in nearly all cases; only two blades were removed from platforms in two directions. 


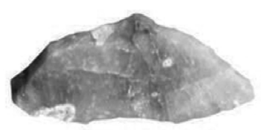

1

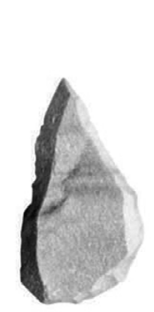

2

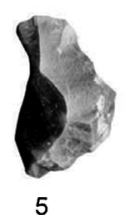

5

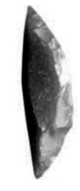

6

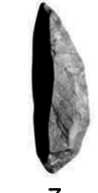

7

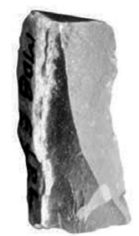

11

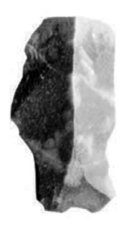

12

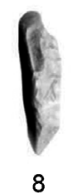

8

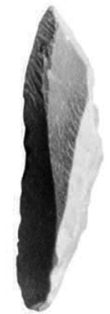

3

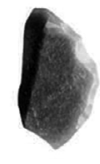

9

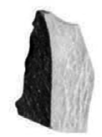

15

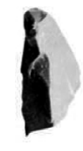

10

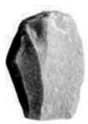

16

Fig. 13. Microliths and retouched blades from Mahadebbera: (1) triangle; (2-4) points; (5-10) lunates; (11-16) backed blades.

Compared to the findings at Mahadebbera, the findings at the Kana site potentially date much earlier, as they are associated with an OSL date of $42 \pm 4 \mathrm{ka}$. The 20 flakes recovered at a depth of $1.34-1.63 \mathrm{~m}$ in Unit 2 were most clearly associated with this oldest date. These individual pieces were consistent with the debitage of microblade manufacture as seen at Mahadebbera, although the dating extended earlier.

In contrast to the total absence of raw material at Mahadebbera, the samples from Kana did contain a few rare nodules of raw material. The low frequency of raw material does not reflect substantial primary reduction from raw materials directly at the site, however. As seen at Mahadebbera, the Kana assemblage was dominated by the later stages of flake working. Most illustrative of this point, primary decortication flakes were absent, and a small retention of cortex was noticed on 46 percent of the flaking debris.

The flaking cores had clearly been utilized, but they were not entirely exhausted at Kana. A fair amount (about 19 percent) of the cores were still $4 \mathrm{~cm}$ long or longer. 


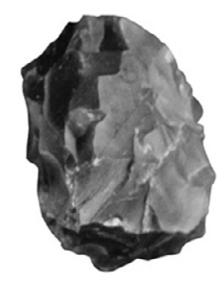

1

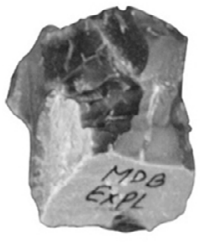

3

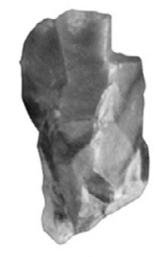

4

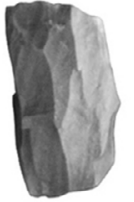

5

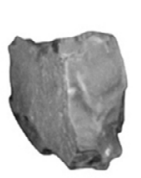

11

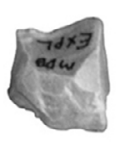

20

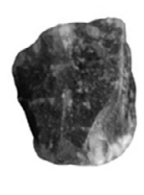

12

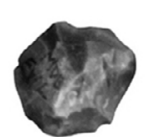

21

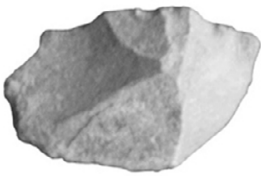

2

17

18

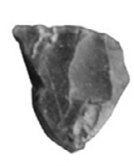

19

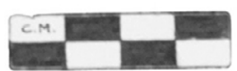

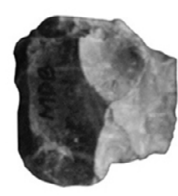

7

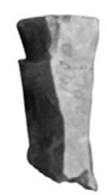

13
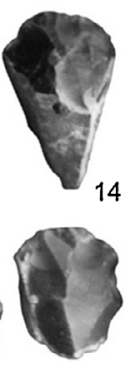

23

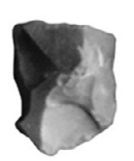

15

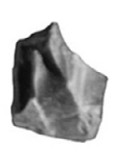

24

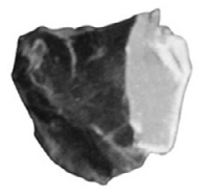

8

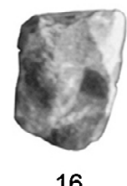

16

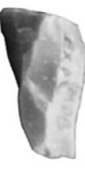

25

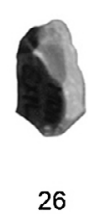

Fig. 14. Microblade cores from Mahadebbera: (1-3) cores showing minimal use; (4-20, 22-23, 25) cores showing clear utilization; $(21,24,26)$ exhausted cores.

Most of the cores displayed only one or two flake scars, while 59.4 percent exhibited three to six scars on their dorsal surface. Three trimmed nodules were apparently used for a different mode of flaking reduction than was seen in the bulk of the Kana assemblage or in any of the materials at Mahadebbera. They all measured in the larger size category at $4 \mathrm{~cm}, 5.4 \mathrm{~cm}$, and $6.5 \mathrm{~cm}$ maximum axis length.

Although in the minority of the overall assemblage at Kana, some of the flakes and cores may have related to a slightly earlier stage in the reduction process than was seen in the Mahadebbera materials. Flakes longer than $4 \mathrm{~cm}$ were still rare, but they constituted more of the Kana assemblage (Table 4) than was recorded at Mahadebbera (see Fig. 15). They could not be matched conclusively with the few cores and raw material nodules measured at $4 \mathrm{~cm}$ or longer, and their position within the chaine opératoire has not yet been clarified.

The ratio of 237 flakes to 37 cores $(6.41: 1)$ at Kana was lower than the ratio at Mahadebbera (7.36:1), suggestive of a lesser amount of flaking per core. These circumstances could be viewed as representing an earlier stage in the stone tool reduction process, for instance involving the removal of a lesser number of larger flakes prior to a later stage of removing more numerous smaller flakes. This possibility will 

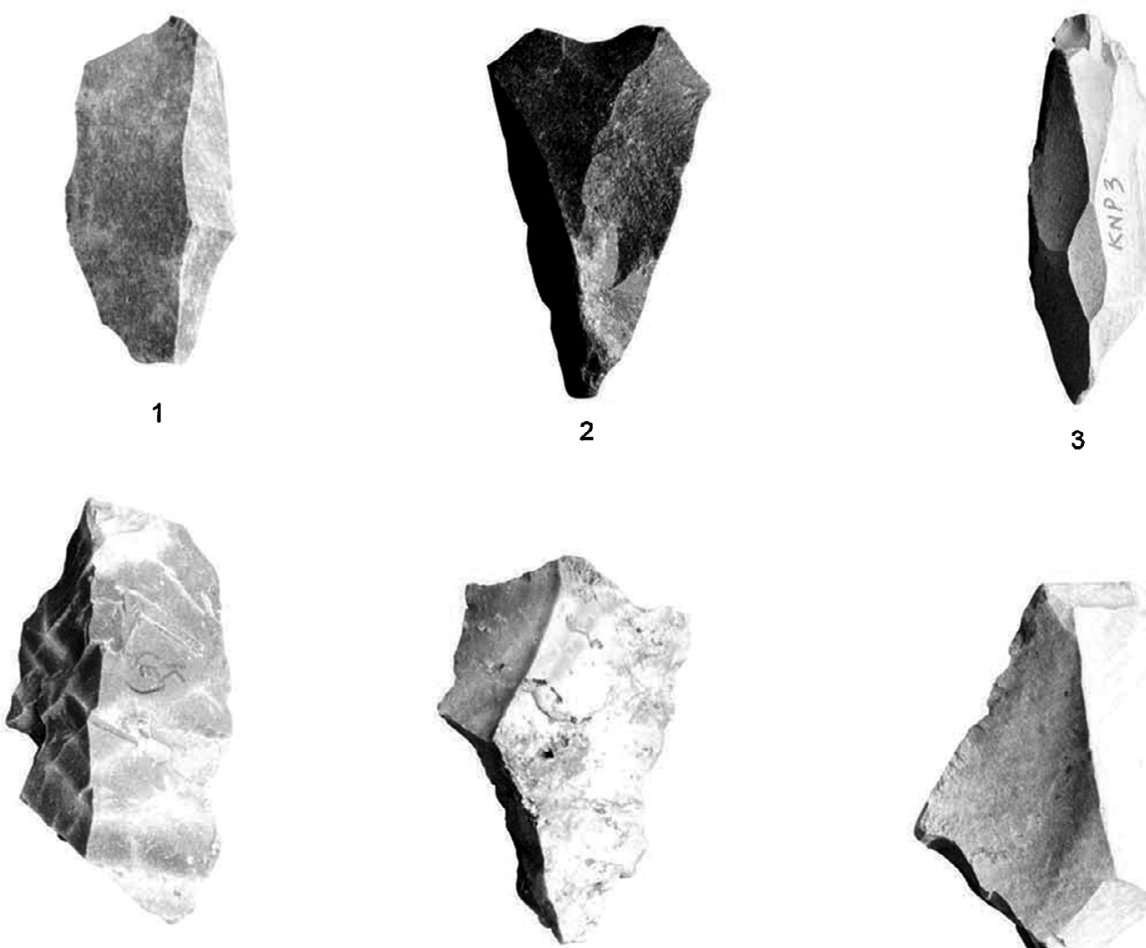

4
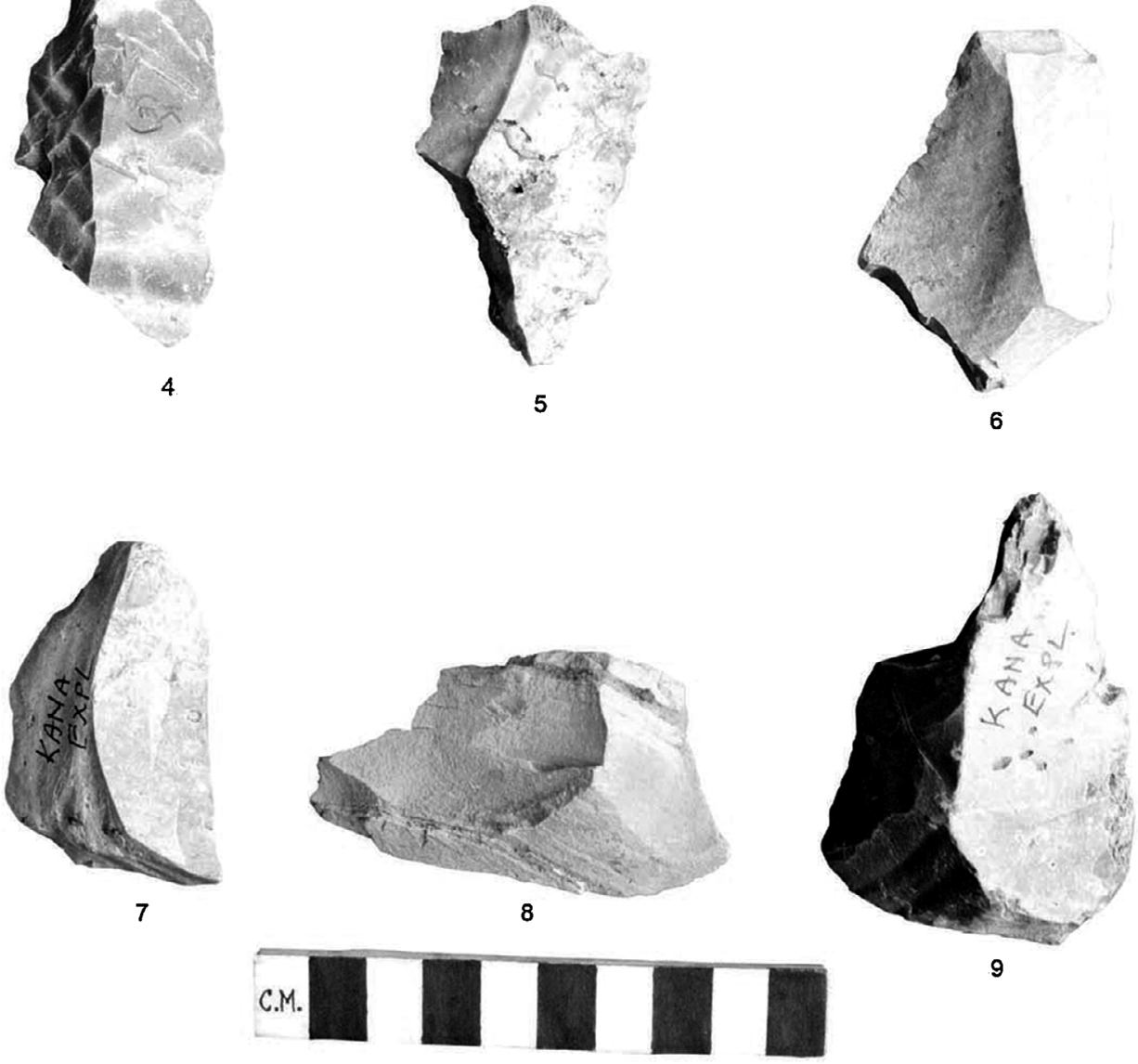

Fig. 15. Flakes 1-9, all maximum lengths $>6 \mathrm{~cm}$ 
Table 2. Microblades and Microliths at Mahadebbera, Surface Context

\begin{tabular}{llllll}
\hline CATEGORY & AVERAGE & $\begin{array}{c}\text { AVERAGE } \\
\text { LENGTH (CM) }\end{array}$ & $\begin{array}{c}\text { MiNimum } \\
\text { LENGTH (CM) }\end{array}$ & $\begin{array}{c}\text { MAXIMUM } \\
\text { LENGTH (CM) }\end{array}$ \\
\hline Microblades & 15 & 0.84 & 2.01 & 1.5 & 2.65 \\
Broken microblades & 37 & 0.82 & 1.74 & 1.01 & 3.38 \\
Backed blades & 14 & 0.8 & 1.9 & 1.2 & 2.66 \\
Points & 12 & 0.8 & 2.2 & 1.54 & 3.56 \\
Lunates & 8 & 0.82 & 1.93 & 1.51 & 2.39 \\
Triangles & 3 & 0.84 & 1.94 & 1.49 & 2.85 \\
Burins & 1 & $\mathrm{n} / \mathrm{a}$ & $\mathrm{n} / \mathrm{a}$ & $\mathrm{n} / \mathrm{a}$ & $2.58^{\mathrm{a}}$ \\
Scrapers & 1 & $\mathrm{n} / \mathrm{a}$ & $\mathrm{n} / \mathrm{a}$ & $\mathrm{n} / \mathrm{a}$ & $2.4^{\mathrm{a}}$ \\
\hline
\end{tabular}

${ }^{a}$ Length of single artifact type recovered.

Table 3. Size Distribution of Flakes at Mahadebbera, Surface Context

\begin{tabular}{llll}
\hline SIZE & SMALL $(\leq 2 \mathrm{CM})$ & MEDIUM $(2-4 \mathrm{CM})$ & LARGE $(4-6$ CM $)$ \\
\hline Totals at Mahadebbera & 130 & 356 & 29 \\
\hline
\end{tabular}

Table 4. Size Distribution of Flakes at Kana, Surface Context

\begin{tabular}{|c|c|c|c|c|}
\hline SIZE & SMALL $(\leq 2 \mathrm{CM})$ AND MEDIUM $(2-4 \mathrm{CM})$ & LARGE $(4-5 \mathrm{CM})$ & LARGE $(5-6 \mathrm{CM})$ & LARGE $(>6 \mathrm{CM})$ \\
\hline Totals at Kana & 171 & 42 & 11 & 13 \\
\hline
\end{tabular}

need further study on a statistically valid numbers of artifacts and this hypothetical scenario may be applicable to only a portion of the total assemblage.

As seen at Mahadebbera, the artifacts at Kana mostly related to microblade production. A minority of the assemblage included larger flakes and cores as noted, but mostly the materials met the criteria of microblades and related cores and debitage. Most of the cores measured 3-4 cm in length, while all of the actual microblades were this long or shorter. Even those rare cores in the larger category $(4-5 \mathrm{~cm}$ long) exhibited much the same blade removal indicators seen in the smaller cores. Furthermore, all sizes of cores revealed flake removal scars that were consistent with the patterns observed in the blades and flaked debris.

\section{CONCLUSIONS}

The OSL dates at Mahadebbera and Kana reported in this article offer the only archaeometric dating so far conducted of the ancient period from $42 \pm 4 \mathrm{ka}$ to $25 \pm 3 \mathrm{ka}$ in West Bengal. This prompts a new appraisal of Pleistocene microlithbearing sites in a larger regional or cross-regional view. The surviving material evidence, limited to microlithic artifacts and their associated sedimentary units, is suitable for addressing issues of technology and location within the landscape. The OSL dating has allowed more precise statements and framing within clearly definable chronological parameters for cross-comparison, previously not possible. 
Microlithic artifacts have been identified in a number of different areas in West Bengal, not only in the Ayodhya Hills as reported here (Fig. 2). Comparable findings have been described in areas to the north, south, and west in the western upland of West Bengal (Chakrabarti 1993:192; Chakrabarti and Chattopadhyay 1984; Chakrabarti et al. 1982; Datta 1991; Datta et al. 1984; Lal 1958; Ray 1991). Likewise in Jharkhand of West Bengal, several instances of microlith-bearing sites have been recorded (Narayan 1996). While detailed studies have only rarely been pursued, the existing reports of sites vaguely referred to as Pleistocene age have allowed assessment of microlithic technologies dispersed across West Bengal (Basak 2007, 2010).

The discoveries in West Bengal can be appreciated as part of a much larger geographic distribution of microliths in India, although the associated dating has not always been clear. A complete inventory is outside the scope of the present work, but some of the more intensively studied areas have been in Orissa, especially in Mayurbhanj (Chakrabarti 2000), Indravati in south Orissa (Nanda 1984), and Darpankhas in coastal Orissa (Sahoo 2000). Additional documentation has been informative for the Burla area of Sambalpur (Behra et al. 1996; Sharma 1994).

Given the OSL dating from $42 \pm 4$ ka to $25 \pm 3 \mathrm{ka}$ for the microlith-bearing sites in West Bengal, the represented contexts must have involved several different episodes within the larger generalized category of Pleistocene behaviors of Homo sapiens. The oldest part of the time range coincided with the inferred age of some of the earliest migrations of anatomically modern humans through this region, though very little hard evidence for this migration survives in the archaeological record. Microliths subsequently continued as essential tools throughout the Pleistocene in West Bengal and in South Asia generally.

These new discoveries in West Bengal add to prior findings of microliths at least as old as $35 \mathrm{ka}$ in Sri Lanka (Clarkson et al. 2009) and probably as old as $45 \mathrm{ka}$ in South Asia as a whole (Mishra et al. 2013). Such an early date range has opened new factbased consideration of the different forms of lithic tool technologies used by Homo sapiens in separate regions or sub-regions. Most intriguing is the possibility that these various technologies might be related to early cross-regional migrations. For instance, Hazarika (2013) has suggested that microlithic tools were used primarily in South Asia, whereas the Hoabinhian type of flaked-pebble tools was used in Southeast Asia.

While microlith-bearing sites have demonstrated general continuity in the use of microliths over a broad region and for tens of thousands of years, naturally a degree of variation must be acknowledged. Even comparing only two sites (Mahadebbera and Kana), variations were noted in flake to core ratios, size distributions of flakes, and represented stages of the tool-production process. OSL dating results were also different, notably older at Kana and younger at Mahadebbera, yet both sites were used during the Pleistocene.

Bearing in mind that the material evidence is limited, it nevertheless demonstrates an emerging pattern of widespread microlithic sites in South Asia during the Pleistocene, traceable at least as early as $42 \pm 4 \mathrm{ka}$ in the case of Kana in West Bengal. Until more sites can be dated confidently, the larger regional patterns cannot be clarified in terms of how Homo sapiens may have migrated through the region. In this case, Groucutt and colleagues (2015) remind us that Homo sapiens dispersals through South Asia may not be explained by single travel routes; the reality may have been more complicated. 


\section{ACKNOWLEDGMENTS}

The authors acknowledge the various individuals and institutions who have supported the present project financially and otherwise: Indian Council of Historical Research, New Delhi; Archaeological Survey of India, New Delhi for license to excavate and explore; Monalisa Rakshit and Debasree Pyne for the maps and Jayati Chatterjee for stone tool line drawings; Debraj Sen for digitization of the section images; and the local administration and people of the Balarampur and Ayodhya hill regions. The second author acknowledges the Director of the Wadia Institute of Himalayan Geology for his support.

\section{REFERENCES CITED}

Acharyya, A., S. Ray, B. K. Chaudhuri, S. K. Basu, S. K. Bhaduri, and A. K. Sanyal

2006 Proterozoic rock suites along South Purulia Shear Zone, Eastern India: Evidence for rift related setting. Journal of the Geological Society of India 68:1069-1086.

Aitken, M. J.

1998 An Introduction to Optical Dating. London: Academic Press

Bar-Yosef, Ofer, and Steven L. Kuhn

1999 The big deal about blades: Laminar technologies and human evolution. American Anthropologist 101(2):322-338.

BASAK, BISHNUPRIYA

1997 Microlithic sites in the Tarafeni valley, Midnapore district: A discussion. Man and Environment 22(2):11-28.

2001 Microlithic sites in the Western Upland of Purulia: A holistic study (Phase I: The Ayodhya Hills). Pratnasamiksha 6 \& 8:1-28.

2005 Perceiving the landscape: Lithic scatters in Ayodhya Hills, Purulia, West Bengal. Man and Environment 30(2):12-23.

2007 A study in the formation processes of the archaeological record of Chotanagpur Plateau, with special reference to Tarafeni valley, Midnapur district, West Bengal, in Formation Processes and Indian Archaeology: 39-50, ed. K. Paddayya. Pune, Maharashtra: Deccan College Post-Graduate and Research Institute.

2008 Microlithic sites in the Ayodhya Hills: Further investigations at Mahadebbera. Man and Environment 33(2):37-50.

2010 Upper Palaeolithic culture in the Chotanagpur plateau region comprising parts of the modern states of Jharkhand, West Bengal and Orissa: A few observations. Pratnasamiksha, New Series 1:1-8.

2013 Excavation of a microlithic site and exploration in the Ayodhya Hills, Purulia, West Bengal, 2011-12 and 2012-13. Pratnasamiksha, New Series 4:83-87.

Basak, Bishnupriya, Pradeep Srivastava, Sujit Dasgupta, Anil Kumar, and S. N. Rajaguru

2014 Earliest dates and implications of microlithic industries of Late Pleistocene from Mahadebbera and Kana, Purulia district, West Bengal. Current Science 107(7):1167-1171.

Behra, Pradeer K., Premananda Panda, and Neena Thakur

1996 Techno-typological analysis of little artefacts from the Dari-dungari Acheulian sites, Sambalpur district, Orissa. Man and Environment 21(2):13-26.

Bettis, Arthur E. III

2003 Patterns in holocene colluvium and alluvium fans across the prairie-forest transition in the midcontinent USA. Geoarchaeology 18(7):779-797.

Blinkhorn, James, Hema Achyuthan, and P. Ajithprasad

2015 Middle Palaeolithic point technologies in the Thar Desert, India. Quaternary International 382: $1-13$.

Blinkhorn, James, Hema Achyuthan, Michael Petraglia, and Peter Ditchfield

2013 Middle Palaeolithic occupation in the Thar Desert during the Upper Pleistocene: The signature of a modern human exit out of Africa? Quaternary Science Reviews 77:233-238.

Boivin, Nicole, Dorian Q. Fuller, Robin Dennell, Robin Allaby, and Michael D. Petraglia

2013 Human dispersal across diverse environments of Asia during the Upper Pleistocene. Quaternary International 300:32-47. 
Chakrabarti, Dilip K.

1993 Archaeology of Eastern India: Chhotanagpur Plateau and West Bengal. New Delhi: Munshiram Manoharlal Publishers.

Chakrabarti, Dilip K., and R. K. Chattopadhyay

1984 Prehistoric stratigraphy in West Bengal: The evidence from Burdwan and Midnapur. Man and Environment 8:39-48.

Chakrabarti, Subrata

2000 Recent advances in the prehistory of Mayurbhanj, in Archaeology of Orissa, vol. 1: 77-101, ed. Kishore K. Basa and P. Mohanty. Delhi: Pratibha Prakashan.

Chakrabarti, Subrata, D. K. Bhattacharya, and Dilip K. Chakrabarti

1982 The context of microliths at Paruldanga, Santiniketan. Man and Environment 6:150-152.

Chattopadhyay, Girija SAnKar

1992 Geomorphology of Kumari Basin: A review. Geological Survey of India Records 118(3-8):95-103.

Clarkson, Chris, Michael Petraglia, Ravi Korisettar, Michael Haslam, Nicole Boivin, Alison Crowther, Peter Ditchfield, Dorian Fuller, Preston Miracle, Clare Harris, Kate Connell, Hannah James, and Jinu Kosby

2009 The oldest and longest enduring microlithic sequence in India: 35,000 years of modern human occupation and change at the Jwalapuram Locality 9 rockshelter. Antiquity 83:326-348.

DATTA, Asok

1991 Blade and blade tool assemblages of the Upper Palaeolithic and Mesolithic periods: A case study from the Mid-Kasai valley in the Jhargram Sub-Division of Midnapur district, West Bengal. Man and Environment 16(1):23-30.

Datta, Asok K., Dilip K. Roy, and Biswanath Samanta

1984 Chamargora: The microlithic site of Tarafeni Basin, District Midnapur, in The Indian Studies: Essays Presented in Memory of Prof. Niharanjan Ray: 21-30, ed. Amita Ray, H. Sanyal, and S. C. Ray. New Delhi: Caxton Publications.

Dennell, Robin, and Michael Petraglia

2012 The dispersal of Homo sapiens across southern Asia: How early, how often, how complex? Quaternary Science Review 47:15-22.

Finlay, Nyree, Bill Finlayson, and Steven Mithen

2000 The primary technology: Its character and inter-site variability, in Hunter-Gatherer Landscape Archaeology: The Southern Hebrides Mesolithic Project 1988-1998: 553-569, ed. Steven Mithen. Cambridge: McDonald Institute for Archaeological Research.

Groucutt, Huw S., Michael D. Petraglia, Geoff Bailey, Eleanor M. L. Scerri, Ash Parton, Laine Clark-Balzan, Richard P. Jennings, Laura Lewis, James Blinkhorn, Nick A. Drake, Paul S. Breeze, Robyn H. Inglis, Maud H. Devès, Matthew Meredith-Williams, Nicole Boivin, Mark G. Thomas, AND AYLWYN SCALLY

2015 Rethinking the dispersal of Homo sapiens out of Africa. Evolutionary Anthropology 24:149-164.

HaZARIKA, ManjIL

2013 Lithic industries with Palaeolithic elements in Northeast India. Quaternary International 269: 48-58.

James, Hannah V. A., and Michael D. Petraglia

2005 Modern human origins and the evolution of behaviour in the later Pleistocene record of South Asia. Current Anthropology 46:S3-S27.

LAL, B. B.

1958 Birbhanpur, a microlithic site in the Damodar Valley, West Bengal. Ancient India 14:4-48.

Lewis, Laura, Nimal Perera, and Michael Petraglia

2014 First technological comparison of Southern African Howiesons Poort and South Asian microlithic industries: An exploration of inter-regional variability in microlithic assemblages. Quaternary International 350:7-25.

Mellars, P.

2006 Going east: New genetic and archaeological perspectives on the modern human colonization of Eurasia. Science 313:796-800. 
Mellars, Paul, Kevin C. Gori, Martin Carr, Pedro A. Soares, and Martin B. Richards

2013 Genetic and archaeological perspectives on the initial modern human colonization of southern Asia. PNAS 110(26):10699-10704.

Mishra, Sheila, Naveen Chauhan, and Ashok K. Singhvi

2013 Continuity of microblade technology in the Indian Subcontinent since $45 \mathrm{ka}$ : Implications for the dispersal of modern humans. PLoS One 8(7):1-14.

Murray, A. S., and A. G. Wintle

2000 Luminescence dating of quartz using an improved single aliquot regenerative-dose protocol. Radiation Measurement 32:57-73.

NANDA, Siba Charan

1984 Stone Age Cultures of Indravati Basin, Koraput District, Orissa. Ph.D. diss. Poona University, Poona.

NARAyan, BASUdeV

1996 Prehistoric Archaeology of Bihar. Patna: K. P. Jayaswal Research Institute.

Petraglia, Michael, Christopher Clarkson, Nicole Boivin, Michael Haslam, Ravi Korisettar, Gyaneshwar Chaubey, Peter Ditchfield, Dorian Fuller, Hannah James, Sacha Jones, Toomas Kivisild, Jinu Koshy, Marta Mirazon Lahr, Mait Metspalu, Richard Roberts, and Lee Arnold

2009 Population increase and environmental deterioration correspond with microlithic innovation in South Asia ca. 35,000 years ago. PNAS 106(30):12261-12266.

Petraglia, Michael D., Michael Haslam, Dorian Q. Fuller, Nicole Boivin, and Chris Clarkson 2010 Out of Africa: New hypotheses and evidence for the dispersal of Homo sapiens along the Indian Ocean rim. Annals of Human Biology 37(3):288-311.

RAY, RANJANA

1991 Middle Palaeolithic culture in West Bengal, in Studies in Archaeology: 59-66, ed. A. Datta. New Delhi: Books and Books.

Ray, Yogesh, and Pradeep Srivastava

2010 Widespread aggradation in the mountainous catchment of the Alaknanda-Ganga River System: Timescales and implications to hinterland-foreland relationships. Quaternary Science Review 29:2238-2260.

Roberts, Patrick, Nicole Boivin, and Michael Petraglia

2015 The Sri Lankan 'microlithic' tradition c. 38,000 to 3,000 years ago: Tropical technologies and adaptations of Homo sapiens at the southern edge of Asia. Journal of World Prehistory 28 (2):69-112 (first published online 25 June 2015).

SAHOO, DAITARI

2000 Prehistory of Darpankhas (District Jajpur), Coastal Orissa, in Archaeology of Orissa vol. 1: 173-200, ed. K. K. Basa and Pradeep Mohanty. Delhi: Pratibha Prakashan.

Sharma, H. C.

1994 Palaeolithic finds around Burla, District Sambalpur, Orissa. Man and Environment 19(1-2): 286-290. 